\title{
Divulgação de informações ambientais por empresas da área da saúde: uma análise de conteúdo dos websites institucionais
}

\section{Flávia Monaco Vieira ${ }^{1}$ e Vanessa Martins Pires $^{2}$}

\author{
${ }^{1}$ Universidade La Salle. Programa de Pós-Graduação em Avaliação de Impactos \\ Ambientais. Av. Victor Barreto, 2288. Centro. Canoas-RS, Brasil (CEP 92010-000). \\ E-mail: flavia.201910304@unilasalle.edu.br. \\ ${ }^{2}$ Universidade Federal do Rio Grande. Campus Santo Antônio da Patrulha. Rua Cel. \\ Francisco Borges de Lima, 3005. Bom Princípio. Santo Antônio da Patrulha-RS, \\ Brasil (CEP 95500-000).
}

Resumo. A divulgação de informações corporativas permite maior proximidade entre as instituições e seus usuários, podendo ser utilizada como estratégia para redução da assimetria informacional. Levando em consideração a gestão ambiental estratégica, essa pesquisa buscou analisar o nível de divulgação de informações ambientais das empresas da área da saúde. Para tanto, foi realizada uma análise de conteúdo dos websites das onze maiores empresas do setor, estabelecidas no Rio Grande do Sul. Índices de divulgação de informações ambientais foram construídos, permitindo analisar o grau de divulgação global e de informações gerais, socioeconômicas e ambientais. 0 valor médio obtido para o Índice de Divulgação Total (IDT) foi de 0,4714, demonstrando que o nível de transparência das empresas pode ser aprimorado. A categoria de informação socioeconômica obteve o maior índice de divulgação, antecedendo as categorias de informação ambiental e geral. As organizações mais transparentes foram aquelas que disponibilizaram relatórios de desempenho sobre as ações desenvolvidas.

Palavras-chave: Gestão ambiental; Divulgação; Empresas de saúde.

Abstract. Disclosure of environmental information by healthcare companies: $A$ content analysis of institutional websites. The disclosure of corporate information allows greater proximity between institutions and their users, and can be used as a strategy to reduce informational asymmetry. Taking into account strategic environmental management, this research sought to analyze the level of disclosure of environmental information by companies in the health area. To this end, a content analysis of the websites of the eleven largest companies in the sector, established in Rio Grande do Sul State, Brazil, was carried out. Indices of disclosure of environmental information were built, allowing to analyze the degree of global disclosure and
Recebido

$26 / 07 / 2020$

Aceito

$26 / 10 / 2020$

Disponível on line

$27 / 10 / 2020$

Publicado

$31 / 12 / 2020$

Acesso aberto

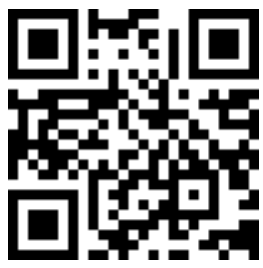

ORCID

(C) 0000-0003-0851-6506 Flávia Monaco Vieira

(D) 0000-0002-1220-2254

Vanessa Martins Pires

ISSN 2359-1412/RBGAS-2020-0113/2020/7/17/12/1197

Rev. Bras. Gest. Amb. Sustent.

http://revista.ecogestaobrasil.net 
general, socioeconomic and environmental information. The average value obtained for the Total Disclosure Index (IDT) was 0.4714 , demonstrating that the level of transparency of the companies can be improved. The category of socioeconomic information obtained the highest value of disclosure, preceding the categories of environmental and general information. The most transparent organizations were those that provided performance reports on the actions developed.

Keywords: Environmental management; Disclosure; Healthcare companies.

\section{Introdução}

A preocupação com as questões ambientais e a busca pela promoção da sustentabilidade nas empresas é estimulada pela crescente demanda social e, muitas vezes, por exigência do mercado. Nesse contexto, a divulgação de informações ambientais no formato on-line, em websites corporativos, tem sido utilizada, buscando maior proximidade das instituições com os seus usuários (Machado, 2013).

As informações ambientais fazem parte de um processo maior que envolve a gestão ambiental da empresa, e esta gestão contempla a administração dos recursos e das operações, visando a preservação do meio ambiente (Monteiro e Ferreira, 2007).

A gestão ambiental corresponde à forma como a empresa age socialmente, economicamente e ambientalmente na busca pela sustentabilidade empresarial. De forma estratégica as empresas visam, por meio da gestão ambiental, obter uma vantagem competitiva, que pode se refletir na satisfação dos clientes, na melhoria de imagem, na redução de custos, na redução dos riscos ambientais, entre outros aspectos.

Empresas prestadoras de serviços na área da saúde são fundamentais para o bem estar da população, tendo como missão a assistência médica, a prevenção e o controle de agravos e de doenças. No entanto, essas organizações podem interagir de forma positiva e/ou negativa no meio ambiente. Em geral, quando a estrutura de negócio das empresas de saúde cresce, favorecendo a prestação de serviços a um número maior de indivíduos, esse crescimento gera um efeito colateral em decorrência do aumento de consumo de recursos naturais, econômicos e tecnológicos.

Nessas empresas, em especial, o gerenciamento adequado dos resíduos deve ser prioridade, pois o manejo inadequado de resíduos dos serviços de saúde pode ocasionar risco à saúde pública e ao meio ambiente. Neste contexto, a Política Nacional de Resíduos Sólidos (PNRS), publicada em 2010, exigiu que as empresas geradoras de resíduos de saúde elaborassem o Plano de Gerenciamento de Resíduos Sólidos (PGRS), devendo mantê-los atualizados e disponíveis aos órgãos competentes (Brasil, 2010).

Ao utilizar a contabilidade como instrumento de mensuração e evidenciação das ações realizadas, as empresas atendem a legislação vigente e ainda podem prestar contas aos seus stakeholders apresentando seus investimentos na preservação ambiental e assumindo a sua responsabilidade socioambiental.

Consciente do impacto ambiental das empresas que atuam na área da saúde e reconhecendo as informações contábeis como um importante instrumento de redução da assimetria informacional entre as empresas e os seus stakeholders, essa pesquisa busca analisar o nível de divulgação de informações de cunho ambiental, disponibilizadas nos sites institucionais das onze maiores empresas do ramo de saúde do Rio Grande do Sul, constantes no ranking das 500 maiores empresas do Sul 2018, divulgado pela Revista Amanhã (2019). 
A pesquisa se justifica pela importância social das empresas prestadoras de saúde na qualidade de vida da população, pelos impactos ambientais gerados durante a prestação dos seus serviços, e ainda pelo seu dever ético de minimizar as externalidades negativas. Em termos de contribuição, os resultados obtidos colaboram com a literatura sobre gestão ambiental e responsabilidade corporativa, ao identificar o grau de preocupação das empresas do ramo de saúde estabelecidas no Rio Grande do Sul em evidenciar o seu desempenho em relação a gestão ambiental. Além de demonstrar a importância da divulgação de informações ambientais aos stakeholders.

A fim de atender ao objetivo dessa pesquisa, a discussão teórica sobre gestão ambiental empresarial e sua utilização estratégica foi realizada. Na sequência, apresentase o método empregado nessa pesquisa e a análise de conteúdo dos websites institucionais, utilizada na identificação das informações ambientais divulgadas pelas empresas pesquisadas. $\mathrm{Na}$ discussão dos resultados apresentam-se os índices de divulgação das informações ambientais (geral, socioeconômica e ambiental) e o índice de divulgação total que foram propostos por essa pesquisa. Por fim, discutem-se as considerações finais e apresentam-se as referências utilizadas como fundamento teórico e metodológico nesse estudo.

\section{Gestão ambiental e estratégia empresarial}

Para alguns stakeholders as organizações são reconhecidas como principais responsáveis pela degradação ambiental. Nesse sentido, Dias $(2019$, p. 5) descreve que, "a industrialização trouxe vários problemas ambientais, como: alta concentração populacional, devido à urbanização acelerada; consumo excessivo de recursos naturais, sendo alguns deles não renováveis (petróleo e carvão mineral, por exemplo); contaminação do ar, do solo, das águas; e desflorestamento, entre outros".

Frente a este cenário, a sociedade passou a questionar sobre o crescimento econômico calcado na destruição da natureza, exigindo uma postura ética e responsável por parte das empresas (Monteiro e Ferreira, 2007). A fim de atender as exigências da sociedade, as organizações buscaram desenvolver habilidades e capacidades que atendam essas demandas e que propiciem uma vantagem competitiva fundada na capacidade da empresa incentivar a atividade econômica ambientalmente sustentável (Santos e Porto, 2013).

Do mesmo modo, a influência dos stakeholders podem estimular as empresas a desenvolverem iniciativas ambientalmente responsáveis, incluindo a responsabilidade socioambiental como objetivo e meta empresarial, determinando estratégicas para atingir tal missão (Ribeiro, 2010). Esse comprometimento responsável por parte das organizações, ao observar os requisitos socioambientais nas atividades desenvolvidas, representa uma tendência mundial irreversível (Hayashi et al., 2015).

A gestão ambiental pode ser considerada como uma alternativa para equilibrar as relações entre a empresa, a sociedade e o meio ambiente. Seu objetivo é conseguir que os efeitos ambientais não ultrapassem a capacidade de carga do meio onde se encontra a organização, garantindo a conservação e a preservação da biodiversidade, bem como a minimização de impactos ambientais das atividades humanas (Machado, 2013; Dias, 2019).

A expressão gestão ambiental é atribuída a uma grande variedade de iniciativas relativas a qualquer problema ou questão ambiental (Barbieri, 2004). Para Guercio e Van Bellen (2006, p. 4), “[...] a gestão ambiental se dá por meio da implementação de programas e ações que reduzem os impactos negativos sobre os meios físicos (água, solo e ar), biológicos (fauna e flora) e sócio econômico, melhorando a qualidade de vida".

Para incorporar a gestão ambiental ao planejamento estratégico, as organizações precisam ser submetidas a uma mudança cultural. Essas mudanças sinalizam a migração 
para um novo contexto empresarial, que pode ser caracterizado como uma gestão de negócios de forma socialmente responsável e ecologicamente correta (Machado, 2013).

Nesse sentido pode-se dizer que, as práticas de gestão ambiental representam um conjunto de novos valores que devem ser incorporados à gestão estratégica da organização, que definem posturas, a relação com seus meios e orientações das opções de negócios (Almeida et al., 2018).

As organizações podem adotar estratégias ambientais, por vários motivos, entre os principais constam: a) a competitividade; b) a maior satisfação do cliente; c) a melhoria da imagem da empresa; d) as conquistas de novos mercados; e) a redução de custos; e f) a redução de riscos (Machado, 2013).

Nunes et al. (2018) contribuem nesta discussão e mencionam que dentre os aspectos positivos para a implantação da gestão ambiental empresarial, pode-se citar a satisfação dos clientes e a criação de vantagem competitiva diante da concorrência, que está cada vez mais acirrada na geração de valor para sociedade.

Machado (2013) compreende que somente a visão do lucro é insuficiente para alcançar os objetivos da empresa, sendo necessário atender às necessidades de todos os agentes envolvidos e empenhar esforços em ações de bem estar para os funcionários e para a sociedade com ênfase no aspecto ambiental.

Não obstante, Santos e Barroso (2019), entendem que as preocupações ambientais das empresas são superiores ao interesse de proteção ambiental, tendo por finalidade obter vantagens competitivas sobre suas concorrentes.

Deste modo, as questões ambientais podem ser inseridas no contexto empresarial, "transformando o risco ambiental em oportunidades de redução de custos, proteção das bases de sustentabilidade do negócio, proteção da imagem corporativa, o que resulta na diminuição de perdas e valorização dos recursos de todos os envolvidos dentro e fora da empresa" (Machado, 2013, p. 13).

Em termos de competitividade, a gestão ambiental tem adquirido uma posição de destaque no meio empresarial, devido aos benefícios que traz ao processo produtivo, além de potencializar alguns outros fatores em particular (Dias, 2019).

As organizações que buscam a melhoria dos seus serviços e produtos precisam estar em constante reavaliação de seus procedimentos, inclusive as variáveis ambientais, com foco na redução dos impactos ambientais, gestão ambiental adequada à legislação, redução de custos e fortalecimento da imagem (Hayashi et al., 2015).

A respeito da percepção dos consumidores, Santos e Barroso (2019) concluíram em sua pesquisa, que a maioria prefere marcas e produtos de empresas que respeitem 0 meio ambiente, e caso as empresas venham a desrespeitar o meio ambiente, os consumidores costumam optar pela troca de marca/produto, além de buscarem informações empresariais sobre as questões ambientais, a fim de verificar se a empresa zela pelo meio ambiente. Esse resultado demonstra que a conduta social e ambientalmente responsável pode ter impacto direto no resultado das empresas.

Existe uma expectativa de que os agentes do mercado valorizem as empresas que demonstram bom desempenho ambiental, além de contribuir para a melhoria da reputação corporativa. Por conseguinte, a empresa que detém uma boa reputação possui vantagem competitiva frente aos concorrentes. Não obstante, traçar estratégias de gestão que impulsionam uma conscientização ambiental sobre as atividades empresariais, comprometidas com a responsabilidade socioambiental, são um desafio constante e crescente (Machado, 2013). Na percepção de Guercio e Van Bellen (2006) as organizações utilizam como estratégia de comunicação e marketing, demonstrações de responsabilidade e atividades que se relacionam com a qualidade de vida da sociedade de maneira sustentável e menos poluidora.

A evidenciação de informações corporativas pode influenciar as percepções dos stakeholders, além de assegurar relações mutuamente benéficas entre esses agentes, seja 
por meio da comunicação compulsória (demonstrações financeiras e relatórios notas explicativas) como também por comunicação voluntária (divulgação de informações em websites, apresentações de analistas por meio de teleconferências e imprensa) (Portella, 2017).

\section{Evidenciação ambiental em websites}

O objetivo da evidenciação da informação ambiental "é divulgar, para os stakeholders, informações sobre o desempenho das entidades nas questões ambientais, bem como divulgar toda a informação que afete o meio ambiente e o patrimônio das entidades" (Monteiro e Ferreira, 2007, p. 87). A evidenciação de informações ambientais pode ser compreendida como uma prestação de contas da empresa para a sociedade, possibilitando avaliar o relacionamento da organização com o meio ambiente (Rosa et al., 2011).

A evidenciação de informações ambientais, segundo Monteiro e Ferreira (2007, p. 83), "está em consonância com os princípios de responsabilidade social corporativa, que prega, entre outras coisas, a ética na condução dos negócios, a transparência no relacionamento com os stakeholders e o compromisso da empresa com o desenvolvimento sustentável”.

Apesar da divulgação de informações de cunho ambiental ainda ser baixa, aparentando desconhecimento ou desinteresse sobre esse aspecto da responsabilidade social (Monteiro e Ferreira, 2007), percebe-se que importantes mudanças têm ocorrido, na última década, na qual os gestores têm enriquecido os relatórios anuais com informações, ainda que limitadas às informações de natureza qualitativa (Ribeiro, 2010).

Ao analisar as estratégias relacionadas à evidenciação ambiental, os gestores levam em considerações alguns fatores, dentre eles: "o entendimento que o meio ambiente é uma fonte esgotável; a responsabilidade profissional e o sistema complexo que envolve o tema (diversos atores, sistemas e interesses)" (Rosa et al., 2011, p. 158).

As empresas, que visam demonstrar seu compromisso com a sociedade e sua responsabilidade social, utilizam diversos recursos, que vão desde campanhas de marketing até a divulgação de relatórios de ações sociais e ambientais, passando pela criação de departamentos para gerir as questões socioambientais (Monteiro e Ferreira, 2007).

Sabe-se que algumas organizações passaram a evidenciar informações relacionadas aos seus gastos com ações ambientais para promover a sua imagem e seus produtos ou serviços. Embora haja críticas pelo excesso de marketing na elaboração dos relatórios sociais, Ribeiro (2010, p. 108) destaca que, "é preciso reconhecer o fator positivo: a informação prestada tem estimulado os concorrentes a realizar ações semelhantes ou melhores, o que resulta, portanto, no benefício da sociedade como um todo".

Em um passado recente, as empresas só possuíam relatórios impressos para divulgar suas informações, no entanto com o advento da internet, as estratégias de evidenciação têm sido repensadas, especialmente pela facilidade de acesso às informações no formato online. Aproveitando esse cenário, as organizações têm utilizado os websites coorporativos como meio de comunicação da gestão ambiental entre as organizações e os seus stakeholders.

Patten e Crampton (2004) sugerem que o uso da internet pode ser uma ferramenta potencialmente poderosa para divulgar informações ambientais e aumentar a responsabilidade corporativa.

\section{A gestão ambiental e a contabilidade}

A crescente discussão sobre os impactos ambientais causados pelas empresas revelou a importância da contabilidade como uma poderosa ferramenta de gestão. Maia et 
al. (2019, p. 22), descreve que a Contabilidade da Gestão Ambiental é "um instrumento relativamente novo de gestão ambiental, inicialmente projetado para identificar e controlar os custos ambientais e os fluxos físicos do ambiente", mas seus contornos têm sido expandidos.

Muitas organizações associam a preservação ambiental aos custos e despesas, e por isso acabam rejeitando os investimentos com essa finalidade, desconhecendo que é possível lucrar e ainda assim proteger o meio ambiente. Por exemplo, para diminuir o grau de poluição, as empresas podem investir em tecnologias verdes, cujo investimento acaba gerando a diminuição de custos, atraindo clientes e consumidores, contribuindo com a inovação, entre outros aspectos positivos (Santos et al., 2019).

Segundo Santos et al. (2019, p. 16) "a classificação dos benefícios ambientais dá-se da seguinte maneira: redução de custos por meio da otimização de recursos, redução dos custos por meio da eliminação de multas e taxas, redução de custos com a venda de reciclados e redução de custos por meio de economias atuais".

Ciente da importância do tema, a contabilidade, assim como outros ramos do conhecimento, se mobilizou para criar mecanismos que fomentassem a preservação do meio ambiente e, ao mesmo tempo, permitissem fiscalizar e controlar os efeitos sociais e ambientais decorrente do crescimento econômico. Sendo papel da contabilidade, evidenciar as informações sobre fatos e eventos, internos ou externos, que possam afetar o meio ambiente e o patrimônio das entidades (Monteiro e Ferreira, 2007).

"O foco principal da Contabilidade Ambiental é aumentar a consciência sobre a importância de gestão de potenciais positivos e negativos, dos impactos ambientais sobre o desempenho econômico das empresas" (Maia et al., 2019, p. 25). Sendo compreendida ainda como a contabilização dos benefícios e prejuízos que o desenvolvimento de um produto pode trazer ao meio ambiente, considerando a preocupação com o mesmo (Santos et al., 2019).

Vários pesquisadores tem devotado atenção, tanto à necessidade de se evidenciar as informações de natureza sócio-econômico-ambientais, quanto ao modo adequado de divulgação e ao conteúdo da evidenciação (Maia et al., 2019). Essa preocupação vem ao encontro de objetivos e princípios contábeis, uma vez que atende ao princípio da oportunidade, que consiste no registro dos fatos no momento em que eles ocorrem desde que possam ser tecnicamente estimados, e ao princípio da continuidade, revelando a verdadeira situação patrimonial da empresa, quanto aos riscos ambientais inerentes ao seu negócio, bem como os passivos ambientais gerados pelas atividades (Monteiro e Ferreira, 2007).

A evidenciação ambiental voltada para a gestão empresarial deve ser capaz de informar o desempenho ambiental, o que envolve o registro de contas patrimoniais e de resultados que envolvem os investimentos ambientais, dados sobre consumo de recursos naturais, emissões, impactos, responsabilidade socioambiental e questões político-institucionais (Rosa et al., 2011).

Embora tenha havido algumas iniciativas na promoção da evidenciação de eventos ambientais no Brasil, tais iniciativas não lograram continuidade, dentre elas pode-se citar:

I) Pronunciamento com conceitos básicos de contabilidade ambiental (NPA 11 Balanço e Ecologia) do Instituto Brasileiro de Contadores (Ibracon), revogado em maio de 2011.

II) Parecer de Orientação da Comissão de Valores Mobiliários (CVM), emitido em 1987, que recomendava a inclusão de descrição de gastos relacionados com a proteção do meio ambiente, no relatório da administração.

III) NBC T 15 do Conselho Federal de Contabilidade (CFC), emitido em 2004, recomendando a evidenciação de informações de natureza social e ambiental. 
Embora a elaboração das demonstrações contábeis financeiras ambientais seja voluntária, a divulgação de demonstrações adaptadas com informações dos fatos ambientais pode ser considerada como diferencial competitivo para as empresas, além de reconhecida como uma resposta positiva para a sociedade (Santos et al., 2019).

\section{Metodologia}

0 delineamento de pesquisa adotado neste trabalho é de natureza exploratóriodescritiva com abordagem predominantemente qualitativa. 0 universo foi delimitado ao ranking das 500 maiores empresas do Sul do ano 2018, divulgado pela Revista Amanhã (2019).

A consulta foi realizada no dia 15 de fevereiro de 2020, no site <http://www.amanha.com.br/500maiores/>. A Amostra é não probabilística e atendeu aos critérios: a) Indicador: Posição; b) Setor: Saúde; e c) Estado: Rio Grande do Sul (Tabela 1).

Tabela 1. Amostra.

\begin{tabular}{|c|c|c|c|c|c|c|c|c|}
\hline $\begin{array}{c}\text { Posição } \\
2018\end{array}$ & \begin{tabular}{|c|} 
Posição \\
2017 \\
\end{tabular} & Grupo/Empresa & Setor & Cidade & VPG* & \begin{tabular}{|c|} 
Patr. \\
Líquido \\
\end{tabular} & $\begin{array}{l}\text { Receita } \\
\text { Líquida }\end{array}$ & $\begin{array}{c}\text { Lucro } \\
\text { Líquido }\end{array}$ \\
\hline 53 & 57 & Unimed Porto Alegre & Saúde & $\begin{array}{l}\text { Porto } \\
\text { Alegre }\end{array}$ & 1374,25 & 655,85 & 2589,84 & 103,9 \\
\hline 129 & 142 & \begin{tabular}{|c|} 
Irmandade da Santa \\
Casa de Misericórdia \\
de Porto Alegre
\end{tabular} & Saúde & $\begin{array}{l}\text { Porto } \\
\text { Alegre }\end{array}$ & 541,95 & 354,38 & 905,87 & 24,16 \\
\hline 138 & 149 & \begin{tabular}{|c|} 
Associação \\
Hospitalar Moinhos \\
de Vento \\
\end{tabular} & Saúde & $\begin{array}{l}\text { Porto } \\
\text { Alegre }\end{array}$ & 510,06 & 389,84 & 776,3 & 46,23 \\
\hline 173 & 0 & $\begin{array}{c}\text { Unimed Nordeste - } \\
\text { RS }\end{array}$ & Saúde & $\begin{array}{l}\text { Caxias do } \\
\text { Sul }\end{array}$ & 397,34 & 188,62 & 754,75 & 11,35 \\
\hline 213 & 224 & Cabergs Saúde & Saúde & $\begin{array}{l}\text { Porto } \\
\text { Alegre }\end{array}$ & 298,24 & 458,05 & 158,77 & 57,13 \\
\hline 248 & 0 & $\begin{array}{c}\text { Associação } \\
\text { Hospitalar } \\
\text { Beneficente São } \\
\text { Vicente de Paulo }\end{array}$ & Saúde & $\begin{array}{l}\text { Passo } \\
\text { Fundo }\end{array}$ & 229,56 & 134,52 & 413,95 & $-32,76$ \\
\hline 269 & 0 & \begin{tabular}{|c|} 
Unimed Vale do \\
Taquari e Rio Pardo \\
\end{tabular} & Saúde & Lajeado & 202,64 & 114,73 & 361,57 & 6,48 \\
\hline 278 & 0 & $\begin{array}{l}\text { Unimed Vale dos } \\
\quad \text { Sinos }\end{array}$ & Saúde & $\begin{array}{c}\text { Novo } \\
\text { Hamburgo }\end{array}$ & 195,19 & 121,57 & 334,89 & 4,47 \\
\hline 350 & 366 & $\begin{array}{l}\text { Centro Clínico } \\
\text { Gaúcho Ltda }\end{array}$ & Saúde & $\begin{array}{l}\text { Porto } \\
\text { Alegre }\end{array}$ & 135,73 & 46,63 & 276,96 & 16,36 \\
\hline 351 & 0 & Unimed Santa Maria & Saúde & Santa Maria & 134,75 & 56,21 & 264,87 & 7,03 \\
\hline 495 & 0 & Unimed Pelotas & Saúde & Pelotas & 67,35 & 25,97 & 135,74 & 0,7 \\
\hline
\end{tabular}

Fonte: Baseado na Revista Amanhã (2019). Legenda: VPG* = Valor Ponderado de Grandeza; Patr. Líquido = Patrimônio líquido. 
o Valor Ponderado de Grandeza (VPG*), presente na Tabela 1, é o índice que reflete, de forma equilibrada, o tamanho e o desempenho das empresas, a partir do resultado da soma de $50 \%$ do patrimônio líquido, $40 \%$ da receita bruta e $10 \%$ do lucro (prejuízo) líquido do exercício (Revista Amanhã, 2019).

A técnica de análise do conteúdo foi empregada na análise dos dados. Em especial, no que se refere à divulgação de informações sobre a gestão ambiental nos websites institucionais das empresas apresentadas na Tabela 1.

A consulta aos websites foi realizada no período do dia 16 a 20 de abril de 2020. A análise dos dados foi realizada de forma objetiva e rigorosa, considerando o emprego dos mecanismos de busca e coleta de dados para todas as páginas, observando as particularidades de cada organização, no que se refere ao formato dos websites institucionais.

A consulta aos websites envolveu a coleta de informações presentes em todos os relatórios e documentos publicados nessas páginas, sendo utilizados os dados mais recentes divulgados, tendo algumas empresas disponibilizados os documentos datados de 2018, outras com dados mais atualizados, do exercício de 2019.

Para verificar o tipo e o grau de divulgação de informação sobre a gestão ambiental, utilizou-se uma listagem constituída por 20 itens, divididos em três categorias de informação: Geral, Socioeconômica e Ambiental (Tabela 2). A metodologia empregada foi adaptada de Ribeiro et al. (2018), que investigou a divulgação on-line de informação sobre a responsabilidade social nos municípios portugueses.

A metodologia consiste na codificação das informações qualitativas em categorias pré-definidas, utilizadas para verificar as práticas de divulgação e a criação de Índices de Divulgação, de modo a medir o nível de divulgação de informações ambientais. As categorias: Informações Gerais, Informações Socioeconômicas e Informações Ambientais são compostas por alguns elementos observados durante a coleta dos dados, os quais foram descritos a seguir:

Informações Gerais - verificou-se a presença de um link próprio sobre a gestão ambiental/sustentabilidade; uma política ambiental expressa; referência à existência de uma comissão de trabalhadores ou representantes dos trabalhadores; e a identificação dos grupos de interesses da organização.

Informações Socioeconômicas - investigou-se a divulgação de gastos com investimentos ambientais, com as despesas ambientais e com programas sociais; a presença de informações sobre o desenvolvimento de programas sociais, sobre os trabalhadores; e sobre os programas voltados para saúde, higiene e segurança no trabalho; e disponibilização do código de ética/conduta.

Informações Ambientais - verificou-se a divulgação de iniciativas que visam a atenuar os impactos ambientais das atividades desenvolvidas; revelação do consumo de energia, volume de água utilizada e reaproveitada, e emissões para atmosfera; informações sobre resíduos gerados internamente, redução/reutilização/reciclagem de materiais, coleta e disposição dos resíduos de saúde; informação sobre o relacionamento com os fornecedores na busca por boas práticas ambientais e divulgação de certificações.

Na Tabela 2 consta o número de itens observados em cada categoria.

Tabela 2. Categorias de Informações.

\begin{tabular}{|l|l|}
\hline Categoria 1 - Informação Geral & 4 itens \\
\hline Categoria 2 - Informação Socioeconômica & 7 itens \\
\hline Categoria 3 - Informação Ambiental & 9 itens \\
\hline
\end{tabular}


O conteúdo dos websites referente as onze empresas selecionadas foram analisados, bem como os documentos divulgados, tentando detectar a presença ou ausência da informação referente a cada um dos itens que constituem a listagem, atribuindo-se uma ponderação de 0 ou 1 , de acordo com o seguinte critério:

0 - 0 item não é divulgado;

1 - 0 item é divulgado.

Tratando-se de um método de indicador de presença ou ausência, o valor 1 é o máximo que pode ser atribuído a cada item, para cada empresa, independentemente de o website divulgar várias vezes a informação relativa a um item.

Embora esta metodologia não permita analisar a qualidade, nem a quantidade de informação divulgada, reconhecendo apenas se existe ou não alguma divulgação relativa a cada item, ela permite a medição objetiva do nível de divulgação da informação contida. (Ribeiro et al., 2018).

Com a finalidade de medir o nível de divulgação de informação sobre a gestão ambiental das empresas analisadas foi criado um Índice de Divulgação, que engloba todos os itens de informação anteriormente definidos. Para cada categoria de informação também foi criado um sub-índice de divulgação que integra os itens de cada categoria.

O valor atribuído para cada índice de divulgação (Índice Divulgação Geral - IDG; Índice de Divulgação Socioeconômica - IDS; e Índice de Divulgação Ambiental - IDA) é calculado pelo quociente entre a pontuação total obtida por cada categoria e o número máximo de itens que a constituem, conforme se descreve abaixo (Equação 1), sendo que o valor de cada índice varia entre 0 e 1.

$$
\mathrm{IDx}_{\mathrm{j}}=\sum_{n=1}^{\mathrm{I}} \mathrm{i}_{\mathrm{n}} / \mathrm{i}
$$

Equação 1.

Sendo:

$I x_{j}$ = Índice de Divulgação de Informação (Categoria X) da empresa $\mathrm{j}$

$\mathrm{i}_{\mathrm{n}} \quad=$ Item geral $\mathrm{n}$ em análise variável dicotômica com valor 1 se a empresa divulga $\mathrm{o}$ item e valor 0 caso não divulga o item $n$.

$\mathrm{i}$ = Número máximo de itens de informação da categoria $\mathrm{X}$

No que diz respeito ao Índice de Divulgação Total (IDT), o que se pretende é determinar a existência ou não de divulgação de informação relativa à gestão ambiental de uma forma equilibrada, razão pela qual se optou pela atribuição da mesma ponderação a cada categoria. Desta forma, o Índice de Divulgação Total de Informação sobre Gestão Ambiental (IDT) é calculado com uma ponderação de $1 / 3$ de cada um dos índices de informação específica: IDG, IDS e IDA. 


\section{Resultados e discussão}

Neste capítulo são apresentados os resultados referentes aos itens de informações que foram divulgados pelas empresas distribuídos em três categorias: Divulgação de Informação Geral sobre a Gestão Ambiental (IDG), Divulgação de Informação Socioeconômica (IDS) e Divulgação de Informação Ambiental (IDA). Na sequência apresentam-se os resultados dos índices de divulgação sobre a gestão ambiental propostos nesta pesquisa para as onze empresas analisadas.

\section{Evidenciação da gestão ambiental}

A análise de conteúdo permitiu identificar se as empresas informaram ou não cada um dos 20 itens relacionados na listagem pré-estabelecida, dividida em 3 categorias de informação (Geral, Socioeconômica e Ambiental). Caso a empresa tenha divulgado o item, a nota atribuída foi 1 , caso contrário foi 0 .

A Tabela 3 apresenta os dados obtidos, contendo a distribuição de frequências e o percentual de adesão a cada um dos itens.

Tabela 3. Divulgação de informações ambientais por categoria.

\begin{tabular}{|c|l|c|c|}
\hline & informaçães gerais sobre a gestão ambiental & Quantidade & Percentual \\
\hline 1. & Link separado referente à Gestão Ambiental e/ou Sustentabilidade & 5 & $45 \%$ \\
\hline 2. & Política ambiental ou PGRSS expressa & 7 & $64 \%$ \\
\hline 3. & $\begin{array}{l}\text { Existência de uma comissão de trabalhadores ou representantes } \\
\text { dos trabalhadores }\end{array}$ & 1 & $9 \%$ \\
\hline \multirow{2}{*}{4.} & $\begin{array}{l}\text { São identificados os grupos de interesses (stakeholders ou partes } \\
\text { interessadas) da organização }\end{array}$ & 3 & $27 \%$ \\
\hline & Informações socioeconômicas & Quantidade & Percentual \\
\hline 1. & Gastos com investimentos ambientais & 1 & $9 \%$ \\
\hline 2. & Gastos com despesas ambientais & 1 & $9 \%$ \\
\hline 3. & Gastos com os programas sociais & 3 & $27 \%$ \\
\hline 4. & Desenvolvimento de programas sociais & 11 & $100 \%$ \\
\hline 5. & Sobre trabalhadores (no total, formação, faixa etária...) & 8 & $73 \%$ \\
\hline 6. & Programas voltados para saúde, higiene e segurança no trabalho & 11 & $100 \%$ \\
\hline 7. & Código de ética/conduta & 7 & $64 \%$ \\
\hline & Informações ambientais & Quantidade & Percentual \\
\hline 1. & Iniciativas para atenuar os impactos ambientais dos serviços & 7 & $64 \%$ \\
\hline 2. & Consumo de energia & 4 & $36 \%$ \\
\hline 3. & Volume total de água reciclada e/ou reutilizada & 4 & $36 \%$ \\
\hline 4. & Emissões para atmosfera & 4 & $36 \%$ \\
\hline 5. & Coleta seletiva e resíduos gerados internamente & 7 & $64 \%$ \\
\hline 6. & Redução, reutilização e reciclagem de materiais & 6 & $55 \%$ \\
\hline 7. & Coleta e disposição final dos resíduos de saúde & 6 & $55 \%$ \\
\hline 8. & Relacionamento com fornecedores, buscando boas práticas \\
ambientais & 5 & $45 \%$ \\
\hline 9. & Certificações & 8 & $73 \%$ \\
\hline & & & \\
\hline
\end{tabular}

Referente à categoria de informações gerais, observa-se que a maioria das empresas (64\%) divulga informações sobre a sua política ambiental, apresentando as prioridades e objetivos. Contudo, algumas empresas restringiram a sua divulgação ao 
Plano de Gerenciamento de Resíduos Sólidos de Saúde. A divulgação dos demais itens da categoria de informações gerais é reduzida, sendo que somente $45 \%$ das empresas contam com um link específico no website institucional para divulgação dos dados relacionados à gestão ambiental e/ou sustentabilidade. Os relatórios de desempenhos ambientais foram encontrados em links denominados como: "publicação" e "portal da transparência".

Somente uma empresa divulgou a comissão de trabalhadores, não sendo identificada pela maioria a participação dos colaboradores na gestão ambiental, além disso, somente três empresas identificarem de forma objetiva os grupos de interesse na divulgação de informações sobre a gestão ambiental.

Entre as categorias consultadas, a categoria socioeconômica foi aquela que obteve maior incidência de informações, apesar dos dados serem majoritariamente qualitativos. Somente a Unimed Vale dos Sinos divulgou no Balanço Social, os valores de gastos com programas ambientais e campanhas de conscientização ambiental, além de divulgar as despesas ambientais, especificando os valores investidos em: educação e treinamento; serviço externo de gestão ambiental; certificação externa; pesquisa e desenvolvimento; adoção de tecnologias mais limpas; compras 'verdes'; entre outros custos de gestão ambiental.

Apenas três empresas divulgaram os valores gastos com investimento sociais, informando o número de pessoas beneficiadas pelos programas e projetos. A maioria $(73 \%)$ evidencia os dados sobre o perfil do quadro de colaboradores, o que envolve: o número de trabalhadores, o seu gênero, a região geográfica, a faixa etária, entre outros.

A maioria das organizações (64\%) informa e disponibiliza o código de ética/conduta, havendo nos websites institucionais um link específico para esta informação. Todas as empresas têm ampla divulgação sobre programas sociais, além daqueles voltados para a saúde, higiene e segurança no trabalho, inclusive apresentam na Demonstração de Resultado do Exercício (DRE), os valores gastos com Programas de Promoção da Saúde e Prevenção de Riscos e Doenças, conforme orientado pela Agência Nacional de Saúde Suplementar (ANS).

Quanto às informações ambientais, oito empresas, que representam $73 \%$ da amostra, divulgaram suas certificações, além dos prêmios e reconhecimentos conquistados. Enquanto que sete empresas informaram sobre as iniciativas para redução dos impactos ambientais dos seus serviços e sobre o gerenciamento dos resíduos serviços de saúde.

É importante mencionar que segundo orientação da PNRS, deve-se observar a seguinte ordem de prioridade na gestão e gerenciamento de resíduos sólidos: "não geração, redução, reutilização, reciclagem, tratamento dos resíduos sólidos e disposição final ambientalmente adequada dos rejeitos" (Brasil, 2010). Os resíduos dos serviços de saúde que não apresentam risco biológico, químico ou radiológico podem ser encaminhados para reciclagem, recuperação, reutilização, compostagem, aproveitamento energético ou logístico reversa. 0 gerenciamento dos demais grupos que apresentam risco à saúde deve observar a Resolução RDC ANVISA no 222/2018, que trata especificamente sobre o manejo, armazenamento, coleta e transporte dos resíduos e de destino de acordo com o grupo de risco específico (ANVISA, 2018).

Apenas seis instituições informaram as práticas relacionadas à redução ou reutilização de materiais e resíduos gerados internamente, divulgando em alguns casos projetos de reaproveitamento deste material, por exemplo: papel e papelão reciclados que retornam como papel higiênico para uso interno e plásticos de polietileno que viraram sacos de lixo. Algumas empresas disponibilizam em seus pontos de atendimento, coletores ecológicos, permitindo que a comunidade descarte medicamentos vencidos e chapas de raio $\mathrm{x}$, garantindo assim, que estes resíduos tenham o descarte ambientalmente correto.

Das empresas investigadas, cinco divulgaram informações sobre o relacionamento com fornecedores na busca pela qualidade e/ou melhores práticas ambientais, contando

Rev. Bras. Gest. Amb. Sustent., 2020, vol. 7, n. 17, p. 1197-1213. 
com manuais que orientam a forma de avaliação e relacionamento. Do mesmo modo, quatro empresas forneceram dados sobre o consumo de energia elétrica, e entre as informações constam: valor consumido, quantidade e fonte energética. A mesma quantidade de empresas apresentaram iniciativas para economia de água e captação da água da chuva, e a quantidade de emissões e equivalentes de $\mathrm{CO}_{2}$ dos gases de efeito estufa.

Na Tabela 4 consta um ranking decrescente das empresas estudadas, considerando a divulgação de informações ambientais de forma global.

Tabela 4. Ranking de divulgação ambiental total

\begin{tabular}{|l|c|}
\hline Empresas & Divulgação total (\%) \\
\hline Unimed Vale dos Sinos & 85 \\
\hline Unimed Vale do Taquari e Rio Pardo & 85 \\
\hline Assoc. Hosp. Moinhos de Vento & 70 \\
\hline Unimed Porto Alegre & 60 \\
\hline Unimed Nordeste RS & 60 \\
\hline Associação Hospitalar Beneficente São Vicente de Paulo & 55 \\
\hline Irmandade da Santa Casa de Misericórdia de Porto Alegre & 50 \\
\hline Unimed Pelotas & 35 \\
\hline Unimed Santa Maria & 20 \\
\hline Cabergs Saúde & 15 \\
\hline Centro Clínico Gaúcho Ltda & 10 \\
\hline
\end{tabular}

As empresas com maior volume de dados divulgados são a Unimed Vale dos Sinos (85\%) e Unimed Vale do Taquari e Rio Pardo (85\%), seguidos pela Associação Hospitalar Moinhos de Vento (70\%), Unimed Porto Alegre (60\%), Unimed Nordeste RS (60\%) e Hospital São Vicente de Paulo (55\%). A Irmandade da Santa Casa de Misericórdia de Porto Alegre tem apenas $50 \%$ das informações disponíveis. As demais empresas pesquisadas apresentam um menor volume de dados divulgados.

Observa-se que as empresas com maior percentual de divulgação total são aquelas que disponibilizaram em seus websites o Balanço Social (Unimed Vale dos Sinos), o Relatório de Atividade, seguindo os padrões internacionais estabelecidos pela Global Reporting Initiative - GRI (Unimed Nordeste RS e Unimed Vale do Taquari e Rio Pardo), o Relatório Anual (Associação Hospitalar Moinhos de Vento e Irmandade da Santa Casa de Misericórdia de Porto Alegre) e o Relatório Social (Hospitalar São Vicente de Paulo).

Apesar da Unimed Pelotas ter divulgado o Relatório de Gestão, o percentual de divulgação das informações totais é de apenas 35\%. É possível que este resultado esteja relacionado ao fato do relatório ter sido elaboração pela primeira vez, em um novo formato, que teve o propósito de intensificar a implantação dos pilares instituídos pela Política Nacional de Sustentabilidade do Sistema Unimed.

A Unimed Santa Maria tem apenas 20\% das informações totais divulgadas, apesar de constar no website institucional um tópico denominado: Responsabilidade Social, ele contempla somente o projeto Renove - Conscientização e Responsabilidade Ambiental, implantado pela Unidade. As empresas com percentual menor de divulgação foram: Cabergs Saúde (15\%), que apesar de divulgar o relatório de gestão, ele se limita ao aspecto social e ao desempenho financeiro, e Centro Clínico Gaúcho (10\%), cujas informações encontradas referem-se exclusivamente a aspectos socioeconômicos. 


\section{Mensuração dos índices de evidenciação}

Após análise da divulgação dos itens de informação previstos em cada uma das categorias, é importante realizar a análise dos valores obtidos para cada um dos índices de divulgação, o que permite medir o nível de divulgação sobre a gestão ambiental de forma objetiva.

Considerando a totalidade das empresas da amostra, a Tabela 5 resume as medidas estatísticas obtidas para cada dos indicadores individualmente (IDG, IDS, IDA) e para o IDT, proporcionando informações sobre a tendência central dos dados (média) e a localização extrema da amostra em termos de divulgação de informação de cunho ambiental.

Tabela 5. Índices de divulgação: estatísticas descritivas.

\begin{tabular}{|l|c|c|c|}
\hline Índice & Média & Mínimo & Máximo \\
\hline IDG & 0,3636363 & 0 & 1 \\
\hline IDS & 0,5454544 & 0 & 1 \\
\hline IDA & 0,5050505 & 0 & 1 \\
\hline IDT & 0,47138047 & 0 & 1 \\
\hline
\end{tabular}

Em termos globais, a divulgação média total de informações sobre a gestão ambiental apresenta-se abaixo dos 0,5 (IDT = 0,471), revelando que há oportunidade de melhorias na divulgação de informações nas três categorias específicas.

Referente à cada categoria, observou-se que o Índice de Divulgação de Informação Geral (IDG) apresentou o valor de 0,364 , demonstrando que apenas um pouco mais de $1 / 3$ dos itens incluídos nesta categoria são informados pelas empresas analisadas.

A categoria de informação socioeconômica (IDS) apresentou o maior índice de divulgação, 0,545. No entanto, observa-se que a maioria das informações divulgadas nessa categoria é referente aos projetos sociais e de saúde, com poucos dados quantitativos sobre investimentos e despesas ambientais.

0 Índice de Divulgação de Informação Ambiental (IDA) obteve o valor de 0,505, demonstrando que apenas metade dos dados é apresentada pelas empresas.

Considerando que essa pesquisa contemplou as maiores empresas do ramo de saúde estabelecidas no Rio Grande Sul, as quais realizam a gestão dos investimentos ambientais e seguem as legislações vigentes, pode-se presumir que a ausência de divulgação de informações sobre a gestão ambiental, observada em algumas empresas, é uma decisão institucional. Nesse sentido, é importante mencionar que existe espaço para que algumas empresas aprimorem a divulgação das informações ambientais, principalmente considerando o impacto gerado pelas suas atividades. A divulgação de informações ambientais voluntárias nos websites dessas empresas pode ser considerada como uma forma de prestação de contas à sociedade.

Algumas empresas demonstram estar ciente da importância da divulgação de informações ambientais de forma voluntária, apesar do nível de divulgação total de informação ficar um pouco abaixo da média. A Unimed Vale dos Sinos RS (2019), por exemplo, descreve que o Balanço Social tem como foco demonstrar publicamente que o objetivo da organização não é somente gerar lucros, mas também promover o desenvolvimento social. O Balanço Social demonstra de maneira transparente 0 compromisso e a responsabilidade da Unimed Vale dos Sinos para com a sociedade. 
No Relatório de Gestão e Sustentabilidade do ano de 2018, a Unimed Vale do Taquari e Rio Pardo (2019, p. 4) destaca que "como forma de prestação de contas de suas atividades, há 18 anos a Unimed VTRP publica relatórios para a comunidade".

A Unimed Nordeste RS (2019, p. 5), por exemplo, entende que o Balanço Social é uma "espécie de prestação de contas que traduz nosso compromisso e responsabilidade diante da sociedade" e a publicação do Relatório de Sustentabilidade 2018 "atende às exigências de compromissos assumidos como empresa signatária do Pacto Global (ONU)".

O Relatório de Gestão do Hospital Moinhos de Vento (2019) apresenta a síntese e os principais indicadores de algumas das ações desenvolvidas em 2019, além de uma visão sobre objetivos e metas dos próximos anos. De acordo com a Associação Hospitalar São Vicente de Paulo (2019), o Relatório Social demonstra as principais atividades realizadas durante o ano.

Por fim, observa-se que apenas algumas empresas divulgaram informações ambientais em um link com nomenclatura específica nos websites institucionais. A maioria das informações foram evidenciadas em relatórios anexos e/ou em outros links que não referiam-se a informações de cunho ambiental. Nesse sentido, essa pesquisa apresenta dentre as implicações gerenciais já relacionadas, a sugestão de que o website institucional seja melhor explorado pelas empresas da área da saúde, divulgando de forma clara e objetiva as informações ambientais aos stakeholders.

Percebeu-se uma predominância da divulgação de informações ambientais em relatórios complementares às demonstrações contábeis, sendo que os gastos com Programas de Promoção da Saúde e Prevenção de Riscos e Doenças foram os únicos valores encontrados nas demonstrações contábeis. Dessa forma, fica evidente que a contabilidade poderia explorar a natureza desses eventos e evidenciá-los, a fim de contribuir na produção de dados qualitativos e quantitativos como subsidio para tomada de decisões internas e como fonte de informação aos stakeholders.

\section{Considerações finais}

As demandas atuais pela busca do equilíbrio entre a relação do meio ambiente e a produção e consumo de materiais, requerem uma atenção especial do meio corporativo. A gestão ambiental e a evidenciação de dados ambientais podem ser uma forma de atender essa demanda e obter vantagens competitivas.

A divulgação de informações sobre a gestão ambiental permite as empresas apresentarem aos stakeholders suas atividades em prol do meio ambiente. Neste contexto, essa pesquisa buscou analisar o nível de divulgação da gestão ambiental, por meio de consulta aos sites institucionais das onze maiores empresas do setor de saúde do Rio Grande do Sul, constantes no ranking das 500 maiores empresa do Sul 2018, divulgado pela Revista Amanhã (2019).

Constatou-se que todas as empresas da amostra possuem oportunidades de melhorias, quanto à divulgação da gestão ambiental como uma estratégia de negócio, dado que o valor médio do índice de divulgação total observado foi de 0,4713. A categoria de informação socioeconômica foi a que apresentou um maior índice de divulgação (com $0,5454)$, antecedendo as categorias de informação ambiental e geral $(0,5050$ e 0,3636, respectivamente).

Observa-se que as instituições com maior percentual de divulgação total são aquelas que disponibilizam em seus websites relatórios de desempenho, sendo alguns desenvolvidos conforme padrões internacionais, como a adoção da metodologia Global Reporting Initiative (GRI) pelas empresas Unimed Nordeste RS e Unimed Vale do Taquari e Rio Pardo. A publicação destes relatórios é percebida como prestação de contas à sociedade, além de ser um instrumento que demonstra aos stakeholders as ações desenvolvidas durante um determinado período. 
O grau mais elevado de evidenciação foi observado nos programas sociais e programas voltados à saúde, higiene e segurança no trabalho, sendo apresentados por todas as empresas analisadas. Credita-se o desempenho obtido ao fato das empresas pertencerem ao ramo de saúde e seguirem as orientações da Agência Nacional de Saúde Suplementar (ANS).

Outras informações de destaque evidenciadas foram as certificações e prêmios recebidos pelas instituições, seguidos pela preocupação com o impacto ambiental, especialmente no que se refere à gestão dos resíduos de serviço de saúde, indo ao encontro da orientação da PNRS.

Apesar das empresas analisadas possuírem licenciamentos ambientais e seguirem legislações especifica relacionado à execução e à manutenção de suas atividades, o Índice de Divulgação Total (IDT) ficou abaixo de 0,5 , destacando claramente a fraca evidenciação de informações ambientais por parte de algumas das maiores empresas da área de saúde estabelecidas no RS, as quais relegaram a um segundo plano a utilização de informações ambientais como uma estratégia de negócio.

Destaca-se o ineditismo desta pesquisa, dada à proposição de três (3) índices de divulgação de informações de cunho ambiental: Geral, Socioeconômico e Ambiental, que permitem a avaliação objetiva do nível de transparência das empresas e a comparabilidade entre empresas de um mesmo setor. Pesquisas futuras poderiam aplicar os indicadores propostos, a fim de avaliar o grau de evidenciação de informações ambientais de empresas presentes em outros segmentos, relacionando o grau de transparência com o desempenho organizacional, a fim de avaliar se o mercado de fato valoriza as empresas que são ambientalmente responsáveis.

Também se indica a promoção de estudos de casos que avaliem o nível de evidenciação de informações ambientais nas instituições hospitalares, as quais desempenham um importante papel nas comunidades em que estão inseridas (promoção da saúde, pesquisas, ensino, geração de emprego e renda), e que necessitam gerenciar a melhoria da qualidade de seus serviços e maior produtividade com menores custos sociais e ambientais (Martins e Mateus, 2018).

\section{Conflito de interesses}

As autoras declaram não haver conflito de interesses.

\section{Referências}

Almeida, S. S.; Dias, W. S.; Marques, J. S. Gestão ambiental: desenvolvimento e práticas sustentáveis. Revista Científica da AJES, v. 7, n. 13, p. 11-19, 2018.

Associação Hospitalar Beneficente São Vicente de Paulo. Relatório social. 2018. Disponível em: <https://hsvp.com.br/painel/admin/upload/publicacoes/arq-145relatorio_2018-site.pdf>. Acesso em: 16 abr. 2020.

Barbieri, J. C. Gestão ambiental empresarial: conceitos, modelos e instrumentos. São Paulo: Saraiva, 2001.

ANVISA - Agência nacional de Vigilância Sanitária. Resolução RDC no 222, de 28 de março de 2018. Regulamenta as boas práticas de gerenciamento dos resíduos de serviços de saúde e dá outras providências. Disponível em: <http://portal.anvisa.gov.br/ documents/10181/3427425/RDC_222_2018_.pdf/c5d3081d-b331-4626-8448-

c9aa426ec410>. Acesso em: 05 fev. 2020.

Rev. Bras. Gest. Amb. Sustent., 2020, vol. 7, n. 17, p. 1197-1213. 
Brasil. Lei no 12.305, de 2 de agosto de 2010. institui a política nacional de resíduos sólidos; altera a Lei no 9.605, de 12 de fevereiro de 1998; e dá outras providências. Disponível em: <http://www.planalto.gov.br/ccivil_03/_ato2007-2010/2010/lei/ 112305.htm>. acesso em: 05 fev. 2020.

CABERGS Saúde. Portal Cabergs Saúde. Disponível em: <https://www.cabergs.org.br/>. Acesso em: 16 abr. 2020.

CCG-Centro Clínico Gaúcho. Portal do CCG Saúde. 2020. Disponível em: <http://www.centroclinicogaucho.com.br/>. Acesso em: 16 de abr. 2020.

Dias, R. Gestão ambiental: responsabilidade social e sustentabilidade. 3. ed. São Paulo: Atlas, 2019.

Guercio, M. J.; Van Bellen, H. M. Meio ambiente e indústria têxtil: um estudo sobre a aplicação de ferramentas de gestão ambiental no Estado de Santa Catarina e sua repercussão sobre a imagem das empresas. Anais do III Encontro da ANPPAS, 2006. Disponível em: <http://www.anppas.org.br/encontro_anual/encontro3/arquivos/TA29306032006-112512.DOC>. Acesso em: 05 jan. 2020.

Hayashi, C.; Almeida e Silva, L. H. A gestão ambiental e sustentabilidade no Brasil. Periódico Eletrônico Fórum Ambiental da Alta Paulista, v. 11, n. 7, p. 37-51, 2015. https://doi.org/10.17271/1980082711720151222

Hospital Moinhos de Vento. Relatório anual 2019. Disponível em: <https://www.hospitalmoinhos.org.br/wp-content/uploads/2020/05/Relat\%C3\%B3rio2019-VERS\%C3\%830-DIGITAL-1.pdf>. Acesso em: 16 abr. 2020.

Irmandade da Santa Casa de Misericórdia de Porto Alegre. Relatório anual - balanço social. 2018. Disponível em: <https://www.santacasa.org.br/uploads/files/ 1556048538.pdf>. Acesso em: 16 abr. 2020.

Machado, J. G. Gestão ambiental: um estudo à luz de cases empresariais sob perspectivas socioambientais. Porto Alegre: Pontífice Universidade Católica do Rio Grande do Sul, 2013. (Trabalho de conclusão de curso).

Maia, D. A. C.; Saraiva, L. G. M.; Ferreira, A. M. C.; Oliveira, T. E.; Oliveira, P. L. Contabilidade da gestão ambiental como ferramenta fundamental para certificação e sustentabilidade. Revista Diálogos Acadêmicos, v. 8, n. 2, p. 18-30, 2019.

Martins, J. M.; Mateus, M. P. Proposta técnica para instalação da central de resíduos de serviços de saúde em projeto modelo de instituição hospitalar. Tubarão: Universidade do Sul de Santa Catarina, 2018. (Trabalho de conclusão do curso).

Monteiro, P. R. A.; Ferreira, A. C. S. A evidenciação da informação ambiental nos relatórios contábeis: um estudo comparativo com o modelo do ISAR/UNCTAD. Revista de Gestão Social e Ambiental, v. 1, n. 1, p. 82-101, 2007.

Nunes, T. F. B.; Rodriguez, A. M.; Ehlert, E. A. Análise do uso de práticas ambientais como vantagem competitiva: estudo de caso de uma metalúrgica do noroeste do Rio Grande do Sul. Anais do Congresso Nacional de Inovação e Tecnologia, 2018.

Patten, D. M.; Crampaton, W Legitimacy and the Internet: An examination of corporate web page environmental disclosures. Advances in Environmental Accounting \& Management, v. 2, p. 31-57, 2004. https://doi.org/10.1016/S1479-3598(03)02002-8

Portella, A. N. R. Evidenciação ambiental em websites corporativos: um estudo em empresas do Brasil e dos Estados Unidos. Florianópolis: Universidade Federal de Santa Catarina, 2017. (Dissertação de mestrado). 
Revista Amanhã. 500 maiores do sul. 2019. Disponível em: <http://www.amanha.com. br/500maiores/>. Acesso em: 03 de fev. 2020.

Ribeiro, M. S. Contabilidade ambiental. São Paulo: Saraiva, 2010.

Ribeiro, V.; Monteiro, S.; Moura, A. Divulgação de informação na Internet sobre responsabilidade social: evidência empírica nos municípios portugueses. Revista de Gestão Ambiental e Sustentabilidade, v. 7, n. 2, p. 185-209, 2018.

Rosa, F. S.; Ensslin, S. R.; Ensslin, L.; Lunkes, R J. Gestão da evidenciação ambiental: um estudo sobre as potencialidades e oportunidades do tema. Engenharia Sanitária Ambiental, v. $16, \quad$ n. 1, p.157-166, 2011. https://doi.org/10.1590/S141341522011000200009

Santos, B. P.; Silva, J. P.; Santos, N. D. S.; Silva, P. S.; Eduardo, A. S. Contabilidade ambiental: aspectos conceituais do estudo. Anais do III Encontro Internacional de Gestão, Desenvolvimento e Inovação, v. 3, n. 1, 2019. Disponível em: <https://periodicos.ufms.br/ index.php/EIGEDIN/article/view/8647>. Acesso em: 10 fev. 2020.

Santos, P. M. F.; Porto, R. B. A gestão ambiental como fonte de vantagem competitiva sustentável: contribuições da visão baseada em recursos e da teoria institucional. Revista de Ciências da Administração, v. 15, n. 35, p. 152-167, 2013. https://doi.org/ 10.5007/2175-8077.2013v15n35p152

Santos, S. N.; Barroso, A. C. Gestão ambiental e desenvolvimento sustentável como diferencial competitivo. Olhar Científico, v. 5, n. 1, p. 874-892, 2019.

Unimed Nordeste RS. Relatório de sustentabilidade. 2018. Disponível em: <http://www.unimednordesters.com.br/upload20112013/file/13052019-170740_

Relatorio_Sustentabilidade_Unimed_2018.pdf>. Acesso em: 16 abr. 2020.

Unimed Pelotas RS. Relatório de gestão e sustentabilidade. 2018. Disponível em: $<$ https://www.unimed.coop.br/web/relatoriodegestaounimedpelotas2018>. Acesso em: 16 abr. 2020.

Unimed Porto Alegre. 2020. Disponível em: <https://www.unimedpoa.com.br/>. Acesso em: 16 abr. 2020.

Unimed Santa Maria RS. Relatório de administração. 2019. Disponível em: <https://www.unimed.coop.br/documents/1353243/1400214/relatorio-ans30.03.pdf/ 7e6be946-1e53-40ea-96f0-b69b726e6305>. Acesso em: 16 abr. 2020.

Unimed Vale dos Sinos. Balanço social. 2018. Disponível em: <https://www.unimed.coop.br/web/valedosinos/sobre-a-unimed-vs/sustentabilidade/ balanco-social>. Acesso em: 15 abr. 2020.

Unimed Vales do Taquari e Rio Pardo. Relatório de Gestão e Sustentabilidade. 2018. Disponível em: <https://www.unimedvtrp.com.br/wp-content/uploads/2019/08/ GRI_2018_comunidade.pdf>. Acesso em: 15 abr..

Informação da Licença: Este é um artigo Open Access distribuído sob os termos da Licença Creative Commons Attribution, que permite uso irrestrito, distribuição e reprodução em qualquer meio, desde que a obra original seja devidamente citada. 